\title{
The Impact of Echocardiography on Parental Anxiety in Children with Innocent Murmurs
}

\section{(Original Article)}

Fiona H L Ip¹, Margaret Hay², Samuel Menahem²

${ }^{1}$ Faculty of Medicine, University of Melbourne, ${ }^{2}$ Faculty of Medicine, Nursing, and Health Sciences, Monash University, Melbourne, Australia

Correspondence:

Prof S. Menahem

Monash Health

246 Clayton Road, Clayton VIC 3196

Tel: 61395946666

Fax: 61395761352

Email: samuel.menahem@monash.edu

Presented in part at the International Paediatric Congress, Vancouver, Canada, 21 August 2016

\section{Acknowledgements}

This is the author manuscript accepted for publication and has undergone full peer review but has not been through the copyediting, typesetting, pagination and proofreading process, which may lead to differences between this version and the Version of Record. Please cite this article as doi: 10.1111/jpc.14775

This article is protected by copyright. All rights reserved. 
Appreciation is expressed to the parents who participated in the study.

\section{$\underline{\text { Conflicts of Interest }}$}

None

\section{Abstract:}

Aim

Heart murmurs are not uncommon in childhood. Once noted they may induce appreciable parental anxiety even if the likely diagnosis is that of an innocent murmur. This study aimed to clarify if a confirmatory echocardiogram may increase parental understanding and reduce their anxiety even though the murmur had been diagnosed as being innocent by an experienced paediatric cardiologist.

\section{Methods}

Parents of children referred to a paediatric cardiologist for evaluation of a murmur were asked to complete a State Trait Anxiety Inventory (STAI) after the cardiologist's clinical diagnosis of an innocent murmur. The questionnaire was repeated after cross-sectional echocardiography to assess if there was a change in the parental understanding regarding their child's murmur and to review their level of anxiety.

\section{Results}

Over the time available for the study, 62 parents were recruited consecutively wherever possible. Forty-eight (77\%) completed both questionnaires. There was a reduction in the state anxiety level following the echocardiogram in parents who exhibited a high $(n=23)$ or even a low-level trait anxiety $(n=25)(p<0.05)$. Enhanced parental understanding of the diagnosis was also demonstrated.

\section{Conclusions}

Reduced parental anxiety and an increase in their understanding after echocardiography suggested that the procedure may have an important role in the management of innocent murmurs even after the initial reassurance by a paediatric cardiologist. 


\section{Brief points}

\section{What is already known on this topic:}

1. Significant parental anxiety may occur even if the likely diagnosis is that of an innocent murmur

2. Some parents concern about their child's wellbeing persists despite the reassurance and information provided by a paediatric cardiologist

3. Information on the internet and social media may make it more difficult for parents to be reassured in the absence of a definitive diagnostic investigation

\section{What this paper adds:}

1. The majority of parents expected investigations to be done as part of the assessment by a cardiologist

2. Parental understanding of their child's murmur improved after echocardiography

3. Echocardiography together with careful counselling of the parents by cardiologist reduced parental anxiety 


\section{$\underline{\text { Introduction }}$}

Murmurs are common in infancy and childhood and may indicate an underlying cardiac abnormality. Innocent murmurs have an estimated frequency of between $30 \%$ and $60 \%$ of children ${ }^{(1,2)}$. By definition, such murmurs are not associated with anatomical or physiological cardiac abnormalities with the child being asymptomatic ${ }^{(3)}$. Yet such murmurs still cause concerns and are often referred for expert evaluation ${ }^{(2-4)}$. Previous reports have suggested that paediatric cardiologists are excellent at clinically differentiating innocent murmurs from pathologic ones ${ }^{(3,5,6)}$. An echocardiogram may be ordered not only to provide a definitive diagnosis but to reassure both the family and the referring physician ${ }^{(7)}$. Heart murmurs may signify a serious cardiac abnormality, and the diagnosis of a murmur in infancy or childhood understandably may result in anxiety for parents ${ }^{(8-12)}$.

A previous paper reviewed the significant findings found in 3 patients by echocardiography despite the cardiologist's diagnosis of an innocent murmur, namely congenitally corrected transposition of the great arteries without any malformation, anomalous right upper lobe pulmonary venous drainage, and non- 
compaction of the left ventricle ${ }^{(13)}$. The current paper further explores the role of cross-sectional echocardiography in reducing parental anxiety and improving their understanding of the significance of their child's murmur ${ }^{(8)}$. A positive correlation between poor understanding of the murmur and parental anxiety has been reported ${ }^{(8,14)}$ suggesting that parental education is a critical part of the consultation. However, some parents' concerns about their child's wellbeing persists despite the reassurance and information provided by the consultant ${ }^{(9)}$. Knowledge is often sought from the internet and social media even before parents seek further medical advice ${ }^{(15,16)}$. The availability of unvetted and voluminous content may make it more difficult for parents to be reassured in the absence of a definitive diagnostic investigation $^{(14)}$. The current paper explores these questions further.

\section{Methods}

Parents of children were recruited when their infant or child was referred to a paediatric cardiologist for evaluation of a murmur which was subsequently clinically diagnosed as being innocent. As outlined in Figure 1, the parents were asked to complete a questionnaire to explore their understanding of the diagnosis of the innocent murmur following their consultation with, and the explanation by, the paediatric cardiologist, and whether they would describe their child's heart as normal or abnormal. They also completed the State Trait Anxiety Inventory (STAI)(17). Echocardiography was then carried out if clinically indicated or if requested by the referring clinician (general practitioner or paediatrician). That was followed by a further brief consultation with the paediatric cardiologist who informed the parent(s) of the findings of the scan. They then completed a follow- up questionnaire where they were asked similar questions as in the initial questionnaire to determine if there was a change in their understanding of their child's murmur following the echocardiogram, and a second STAI.

The STAI is a self-completed measure of anxiety. It consists of 20 questions developed to distinguish between State (S) and Trait ( $T$ ) Anxiety in adults with 
scores ranging from 20 (low anxiety) to 80 (high anxiety) ${ }^{(17)}$. The S-Anxiety scale evaluates how the respondents feel at the moment the test was taken, whereas the T-Anxiety scale assesses the level of anxiety the person feels in general.

Prior to reviewing the results, the cardiologist was also asked to complete a questionnaire as to the level of confidence he had in making the clinical diagnosis, the reasons for ordering the investigations or any other significant findings.

A non- parametric paired t- test was used in data analysis comparing state anxiety level before and after echocardiography.

Ethics approval was obtained from the relevant institutional body. Informed consent was obtained from the parent(s).

\section{$\underline{\text { Results }}$}

Sixty-two parents were recruited, consecutively wherever possible over three years. Forty-eight parents (77\%) completed both questionnaires which formed the data for the analysis reported here. Their demographic backgrounds are summarised in Table 1. Twelve (25\%) comprised single child families. Thirty-six of the children had no other medical conditions and were not on regular medications. Seven parents reported that their child experienced symptoms which they attributed to the heart prior to their visit to the paediatric cardiologist, including cyanosis, shortness of breath or chest pain on exertion.

All the children were referred for clarification of a heart murmur. Thirty of the referring doctors were general practitioners, 15 were paediatricians, 2 emergency physicians and 1 an anaesthetist. "Innocent murmur" was stated to be the referring diagnosis in only 9 patients. The others just described the presence of a murmur.

On a scale of 1 to 5 with 1 being not confident and 5 being extremely confident, the cardiologist rated 8 diagnoses at scale 4 and 40 at 5 out of 5 . There was $37.5 \%$ 
concordance between parental rating and the specialist's level of confidence. Fortyone parents stated that they felt the cardiologist was very certain of the diagnosis.

All parents reported feeling anxious or uncertain when asked how they felt about their child's murmur. A Trait score of 31 was used as a cut-off to categorise the participants into a high trait anxiety and low trait anxiety groups as it was the median of the entire group, the latter group also including those with a median score of 31 . The individual State scores before and after echocardiography are summarised in Figure 2. There was a 15\% ( $p$ - value <0.05) and 18\% ( $p$ - value <0.05) reduction in the State score after echocardiography in the high trait anxiety and low trait anxiety group respectively (Table 3 ).

Thirty parents expected investigations to be done as part of the evaluation before their visit to the cardiologist (Table 2). When participants were asked how they felt about the investigations ordered after the initial consultation, most participants reported feeling "fine" and "happy" arising from their preference for a confirmed diagnosis. Two parents reported feeling nervous about the results as they did not expect investigations to be done. No parent expected their child to require medication. One parent planned to restrict their child's activity because of the presence of the murmur. In addition, parents were asked to rate the level of reassurance by the specialist on a scale of 0 to 5 after the initial consultation. Eighteen parents rated 5, 25parents rated 4 and the rest rated 3 or below. Of the 8 parents who initially described their child's heart to be abnormal, only 2 continued to feel their child's heart to be abnormal and planned to return to the specialist for follow-up in the future "as a precaution". The other 6 subsequently described their child's heart as normal or "mostly normal".

Six of the echocardiograms showed incidental, non-significant findings -3 revealed a patent foramen ovale and 3 a trivial patent ductus arteriosus on colour Doppler. Four of the parents of the children with these findings belonged to the low anxiety group, the other 2 to the high anxiety group. With careful explanation of and 
reassurance ${ }^{(13)}$ about these incidental findings, all had a reduction in their anxiety except for one in the high anxiety group whose score increased from 25 to 31 . Trivial tricuspid incompetence noted on colour Doppler imaging was considered "physiological" and not commented upon.

\section{Discussion}

Parental understanding of their child's murmur improved after echocardiography. The parent who described her child's heart as abnormal on 2 separate occasions before and after the echocardiogram belonged to the high trait anxiety group with a trait score of 34 and 39 respectively. However, no relationship was found between poor understanding of the murmur and the presence of high anxiety. Parental anxiety was reduced, except in three parents from the high trait anxiety group and one parent from the low trait anxiety group, following echocardiography regardless of the baseline anxiety level. All four parents who demonstrated increased anxiety after echocardiography still described their child's heart to be normal. In addition none of these scans of their children showed incidental findings such as a patent foramen ovale. Unlike previous reports, our study found that parents did not expect their child to be prescribed any medication or physical activity restrictions. Further investigation may reveal what aspects of the process leading to the diagnosis of the murmur caused the parental anxiety and whether echocardiography alone may address these concerns. This information is important as physicians may then tailor their counselling to minimize parental anxiety using echocardiogram in selected cases only. Written information or computer based animations have been found to be beneficial in informing and reassuring the parents about the nature of innocent murmurs ${ }^{(15)}$.

An earlier paper reported three patients having significant abnormal echocardiography findings despite the murmur being considered innocent on repeated examination ${ }^{(13)}$. 
Of importance with respect to this study were the incidental echocardiographic findings such as a patent foramen ovale, a trivial patent ductus arteriosus or trivial (physiological) tricuspid incompetence that may be observed. They may increase parental anxiety as suggested to be one of the reasons why it is undesirable to order echocardiography when the cardiologist is confident of the clinical diagnosis of an innocent murmur. However careful counselling of the parents as to the significance of the incidental findings readily allayed that anxiety as our study failed to identify any correlation between such trivial, incidental findings when detected, and increased parental anxiety.

\section{Limitations}

The study if repeated with multiple cardiologists of varying seniority and counselling skills and done in both a public and private setting may well produce more meaningful results. A repeat of the study to compare the parental response where no echocardiography is offered as occurs in some centres, may further highlight the differences when compared with other centres where such a non-invasive and relatively inexpensive investigation is readily available and almost routinely performed.

\section{$\underline{\text { Conclusions }}$}

This study suggested that detailed echocardiography may further complement the paediatric cardiologist's reassurance that the child's heart is normal despite the presence of a murmur. It appears to lessen the anxiety of the parents of affected children while increasing their understanding that their child may be treated normally. Further study may help tease out the basis of these findings. 


\section{References}

1. Etoom Y, Ratnapalan S. Evaluation of children with heart murmurs. Clinical Pediatrics. 2014;53(2):111-7.

2. Menahem S. How to treat: recognising heart disease in childhood. Australian Doctor. 2008(2008 Dec 5):25.

3. Advani N, Menahem S, Wilkinson JL. The diagnosis of innocent murmurs in childhood. Cardiology in the Young. 2000;10(04):340-2.

4. Mcconnell ME, Adkins III SB, Hannon DW. Heart Murmurs in Pediatric Patients: When Do You Refer? American Family Physician. 1999;60(2):558- 65.

5. Frank JE, Jacobe KM. Evaluation and Management of Heart Murmurs in Children. American Family Physician. 2011;84(7):793- 800.

6. Smith KM. The innocent heart murmur in children. Journal of Pediatric Health Care. 1997;11(5):207-14.

7. Burch M. Innocent cardiac murmurs in children. GP: General Practitioner. 2008:31.

8. Giuffre RM, Walker I, Vaillancourt S, Gupta S. Opening Pandora's Box: parental anxiety and the assessment of childhood murmurs. The Canadian Journal of Cardiology. 2002;18(4):406- 14. 
9. Gladman G. Management of asymptomatic heart murmurs. Paediatrics and Child Health. 2013;23(2):64-8.

10. Simunovic N, Roncevic Z. Innocent Murmurs: Parental Viewpoint, What are the Most Common Misconceptions and How to Avoid Them. Coll Antropol. 2010;34(1):89-92.

11. Geggel RL, Horowitz LM, Brown EA, Parsons M, Wang PS, Fulton DR. Parental anxiety associated with referral of a child to a pediatric cardiologist for evaluation of a Still's murmur. Journal of Pediatrics. 2002;140(6):747-52.

12. McCrindle BW, Shaffer KM, Kan JS, Zahka KG, Rowe SA, Kidd L. An Evaluation of Parental Concerns and Misperceptions About Heart Murmurs. Clin Pediatrics. 1995;34(1):25-31.

13. Ip H., Menahem S. Does Echocardiography Have A Role In The Cardiologist's Diagnosis Of Innocent Murmurs In Childhood? Heart, Lung and Circulation 2019; https://doi.org/10.1016/l.hlc.2019.02.003 14. Wang QF, Hay M, Clarke D, Menahem S. Associations between knowledge of disease, depression and anxiety, social support, sense of coherence and optimism with health related quality of life in an ambulatory sample of adolescents with heart disease. Cardiology in the Young 2014; 24:1, 126-133.

15. Advani N, Menahem S, Wilkinson JL. Innocent murmurs: the perception of the parents versus that of the child. Cardiology in the Young. 2002;12:587- 8.

16. Ha D, Hay M, Menahem S. Educational DVD for Parents of Children with Congenital Heart Disease: A Pilot Study, Journal of Visual Communication in Medicine. 2018, 41:1,18-23

17. McDowell I. The State- Trait Anxiety Inventory. Measuring health: a guide to rating scales and questionnaires. Third Edition ed. New York: Oxford University Press; 2006. p. 1-9. 
$\underline{\text { Tables }}$

\begin{tabular}{|l|c|}
\hline Parent $(\mathrm{n}=48)$ \\
\hline Age $(\mathrm{y})$, average (Range) & $34.4(27-60)$ \\
\hline Gender (Female: Male) & $45: 3$ \\
\hline Education level $\geq$ tertiary qualification & 37 \\
\hline Background & 46 Caucasians; 1 Asian; 1 Indigenous \\
\hline Marital Status as married & $2(1-5)$ \\
\hline Number of children, median (Range) & \\
\hline
\end{tabular}

Table 1. Demographic Background 


\begin{tabular}{|l|l|l|l|l|}
\hline & \multicolumn{2}{l|l|l|}{ Before Echocardiography } & After Echocardiography \\
\cline { 2 - 5 } & Low Anxiety & High Anxiety & Low Anxiety & High Anxiety \\
\hline $\begin{array}{l}\text { Expect investigation as part } \\
\text { of evaluation }\end{array}$ & 14 & 16 & & \\
\hline $\begin{array}{l}\text { Expect medication to be part } \\
\text { of management }\end{array}$ & Nil & Nil & & \\
\hline Plan to restrict child's activity & Nil & 1 & Nil & Nil \\
\hline $\begin{array}{l}\text { Describe their child's heart as } \\
\text { "Abnormal" }\end{array}$ & 4 & 4 & 1 & 1 \\
\hline Expect to return for follow up & & & 6 & 7 \\
\hline
\end{tabular}

Table 2. Parental understanding of their child's heart murmur before and after echocardiography 


\begin{tabular}{|l|l|l|l|}
\hline \multirow{2}{*}{} & \multicolumn{2}{|l|}{ State Score Mean } & P- Value \\
\cline { 2 - 4 } & Before Echo & After Echo & \\
\hline High Anxiety Group (Trait score >31) $(n=23)$ & 34.26 & 27.35 & $<0.01$ \\
\hline Low Anxiety Group (Trait score $\leq 31)(n=25)$ & 28.08 & 23.16 & $<0.01$ \\
\hline
\end{tabular}

Table 3. State Score of STAI before and after echocardiography for both high anxiety and low anxiety groups 


\section{Figures}

1. Patients were recruited if referred to the paediatric cardiologist for evaluation of a murmur

2. Patients were assessed by the paediatric cardiologist

3. Echocardiogram (Echo) and other investigations were ordered

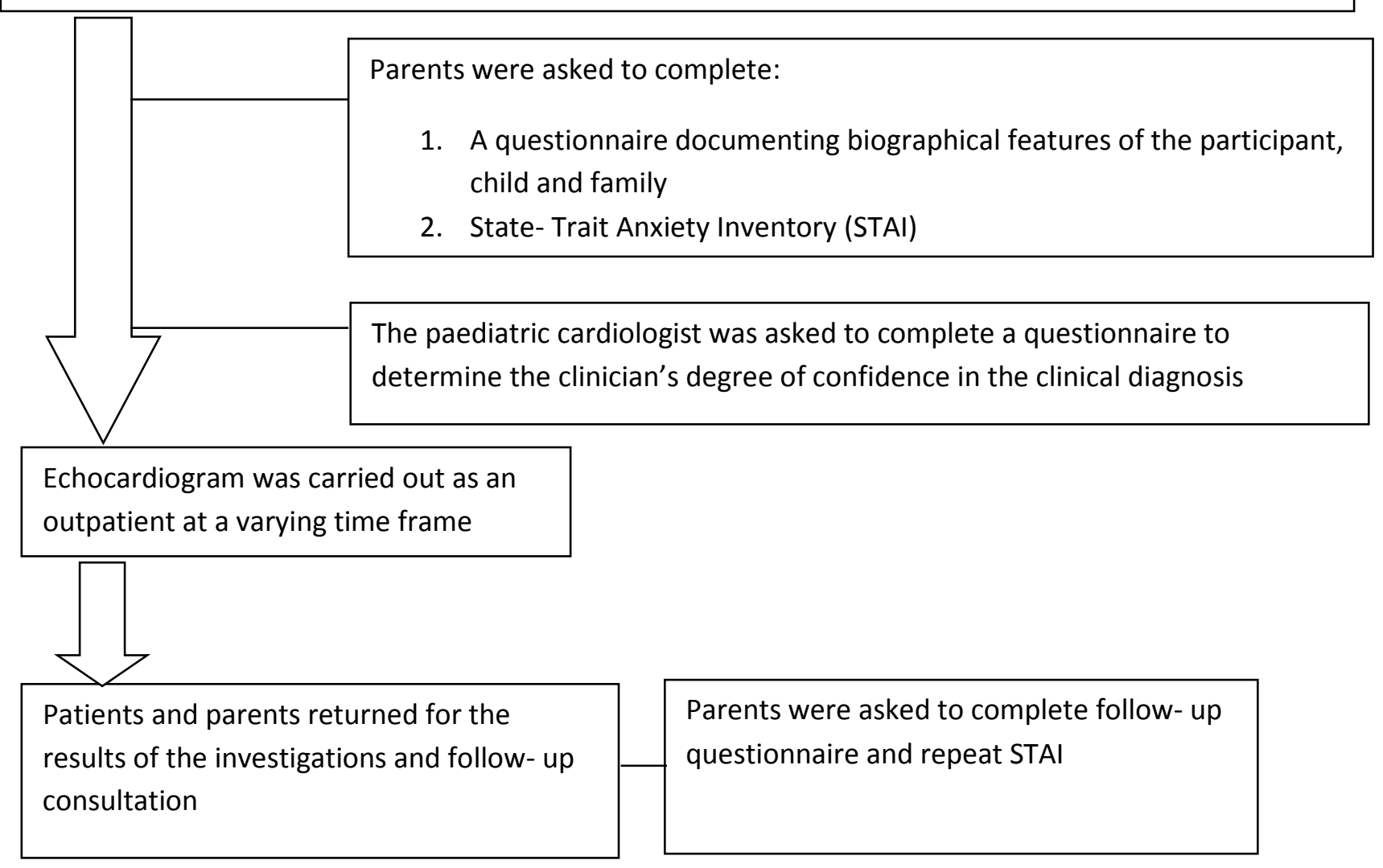

Figure 1: Flow Chart Highlighting Steps in the Study

This article is protected by copyright. All rights reserved. 


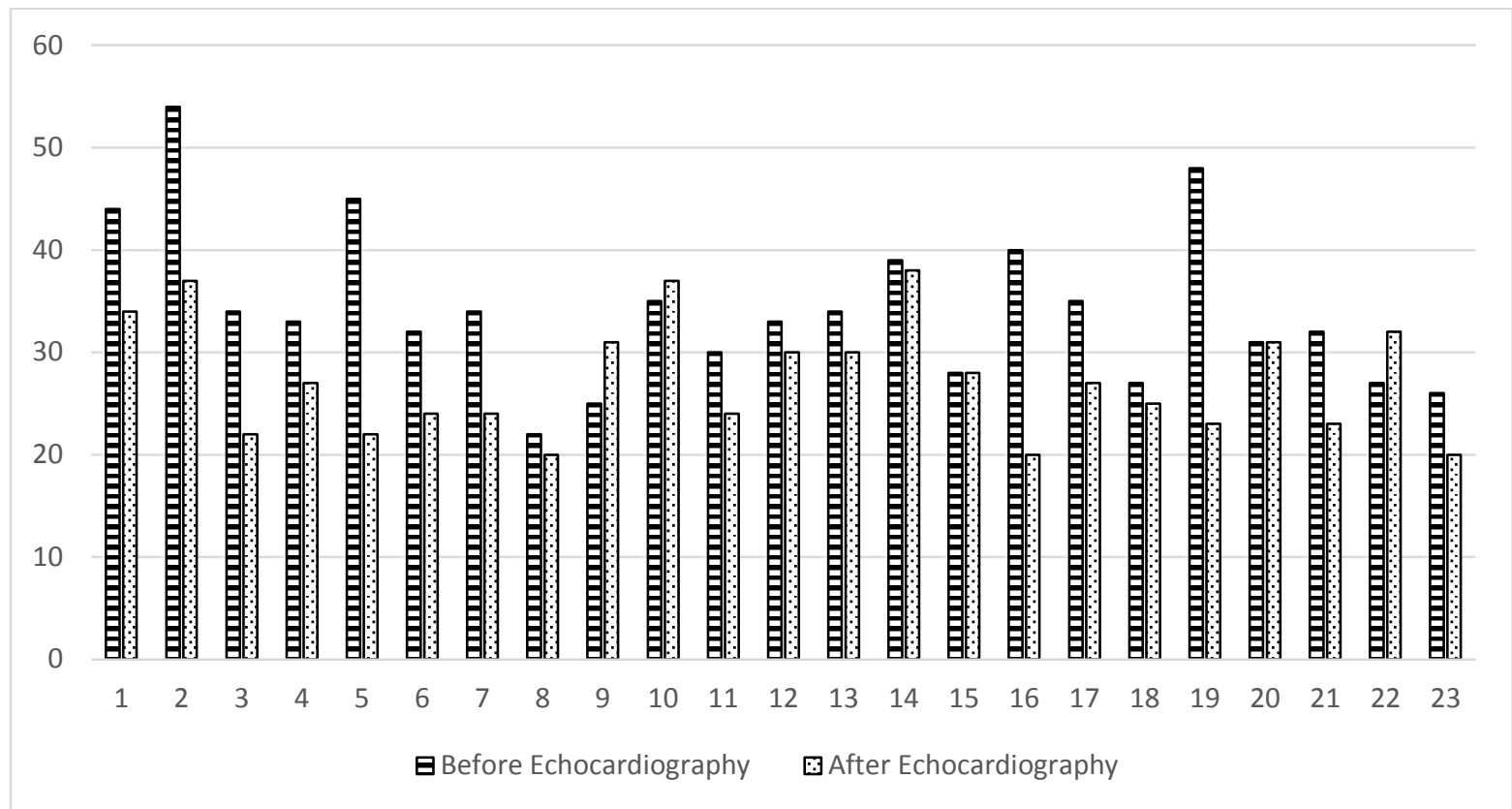

Figure 2. State scores of parents with high- trait anxiety trait scores before and after echocardiography 


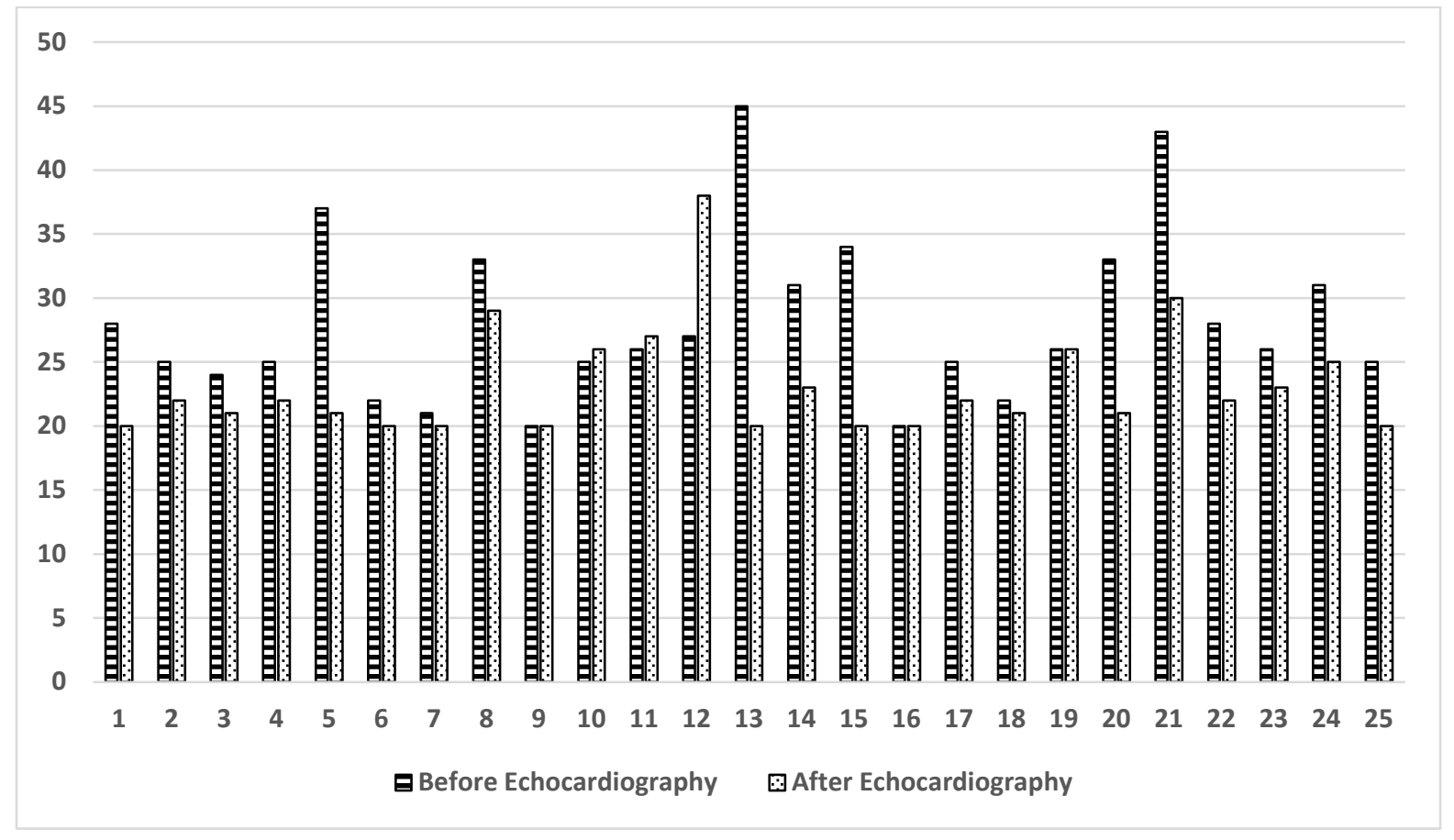

Figure 3. State scores of parents with low- trait anxiety trait scores before and after echocardiography 


\section{The Impact of Echocardiography on Parental Anxiety in Children with Innocent Murmurs}

\section{(Original Article)}

Fiona H L Ip¹, Margaret Hay², Samuel Menahem²

${ }^{1}$ Faculty of Medicine, University of Melbourne, ${ }^{2}$ Faculty of Medicine, Nursing, and Health Sciences, Monash University, Melbourne, Australia

Correspondence:

Prof S. Menahem

Monash Health

246 Clayton Road, Clayton VIC 3196

Tel: 61395946666

Fax: 61395761352

Email: samuel.menahem@monash.edu

Presented in part at the International Paediatric Congress, Vancouver, Canada, 21 August 2016

Acknowledgements

Appreciation is expressed to the parents who participated in the study.

Conflicts of Interest

None 


\section{University Library}

\section{- M M I N E R VA A gateway to Melbourne's research publications}

Minerva Access is the Institutional Repository of The University of Melbourne

Author/s:

Ip, FHL;Hay, M;Menahem, S

Title:

Impact of echocardiography on parental anxiety in children with innocent murmurs

Date:

2020-01-17

Citation:

Ip, F. H. L., Hay, M. \& Menahem, S. (2020). Impact of echocardiography on parental anxiety in children with innocent murmurs. JOURNAL OF PAEDIATRICS AND CHILD HEALTH, 56 (6), pp.917-921. https://doi.org/10.1111/jpc. 14775.

Persistent Link:

http://hdl.handle.net/11343/275273 